\title{
Comparison study for double passive car suspension system through mathematical modelling and experimental work
}

\author{
S. H. Yahaya ${ }^{*}$, S. F. Yaakub ${ }^{1,2}$, F. Ahmad ${ }^{3}$, M. S. Salleh ${ }^{1}$, M. Y. Yuhazri ${ }^{4}$ and S. Akmal ${ }^{4}$ \\ Fakulti Kejuruteraan Pembuatan, Universiti Teknikal Malaysia Melaka, 76100 Durian Tunggal, Melaka, Malaysia ${ }^{1}$ \\ Politeknik Malaysia, Malaysia ${ }^{2}$ \\ Fakulti Kejuruteraan Mekanikal, Universiti Teknikal Malaysia Melaka, 76100 Durian Tunggal, Melaka, Malaysia ${ }^{3}$ \\ Fakulti Teknologi Kejuruteraan Mekanikal dan Pembuatan, Universiti Teknikal Malaysia Melaka, 76100 Durian \\ Tunggal, Melaka, Malaysia ${ }^{4}$
}

Received: 18-June-2021; Revised: 08-September-2021; Accepted: 10-September-2021

(C)2021 S. H. Yahay a et al. This is an open access article distributed under the Creative Commons Attribution (CC BY) License, which permits unrestricted use, distribution, and reproduction in any medium, provided the original work is properly cited.

\begin{abstract}
The purpose of the car suspension was to enhance the safety and comfortability to the driver when driving a car on the road or highway. Car suspension was a system of spring or shock absorbers connecting between the wheels and axles to the chassis of a car. In this study, the comparison between mathematical modelling and experimental work for the ride performance of a passive quarter car model suspension system was shown and discussed. The mathematical modelling of double passive quarter car model suspension system was formulated and solved numerically using the second-order linear differential equation. The outputs from the mathematical modelling were plotted using MATLAB software. The vertical displacement was produced from the mathematical modelling at $0.015 \mathrm{~m}$ identified as a maximum point while the minimum point was at $-0.015 \mathrm{~m}$. The vertical displacements from the experimental work were at $0.02 \mathrm{~m}$ and $-0.03 \mathrm{~m}$ at the minimum point. The comparison showed the oscillation of vertical displacement for the math ematical modelling and the experimental work were identical. All displacements were produced by the mathematical modelling tend to close to its mean which was $0.000176 \mathrm{~m}$ (almost zero). When the zero-displacement achieved, less-vibration was occurred. Due to the finding, the mathematical modelling has showed some potentials to be further explored, especially for predicting the suspension system model.
\end{abstract}

\section{Keywords}

Car suspension system, Double passive system, Second-order linear differential equation, Vertical displacement.

\section{Introduction}

In recent years, car manufacturing has improved with the biggest improvements in terms of the applied technology [1]. With the advent of the latest technology, the suspension system takes the primary role in ensuring the safety and ride comfort of the car. The key to have a good ride comfort is the ability of the vehicle's suspension system to isolate the vehicle's body from the road's imperfections and undulations for the passengers, which would cause an unpleas ant oscillations and accelerations [2].

A quality suspension squarely depends on the behaviour of the car. It supports that the safety of the car would hang on the performance of the suspension system, even though there are many cutting edge technology that is used extensively on the other parts of the car.

\footnotetext{
*Author for correspondence
}

1183
A good suspension systemshould absorb road impact rapidly and could return to its normal position slowly while maintaining an optimal tyre to the road contact [3]. Therefore, the vehicle suspension system tasks for ensuring the ride comfort remains the same while negotiating the unwanted disturbances coming from the various road conditions.

The current passive suspension has the limitation related to the motion of the car's body and the wheel. This limitation also relates to the failure of the velocities to provide the required ride comfort [4]. The design of the automobile suspension system has been to a lens of the study for a long time. An efficient design of an automobile suspension system has been satisfied the ride comfort and better vehicle handling within a reasonable range of suspension deflection [5]. Therefore, the designing and developing of an advanced passive suspension 
system that could provide a better performance of the system becomes the main focus of the study.

Many studies have been done in the field to find out the best optimization in improving the ride comfort, for instance, Amin et al. [6] has performed a detailed experimental work to determine the effects of road excitation on ride comfort. Nonlinear equations are widely used as the models to describe the complex physical phenomena and its significant role in several scientific and engineering fields as noted in [7]. Numerous methods are available in the field such as Rotating Square Evolutionary Operation (ROVOP), gradient based method, genetic algorithm and sequential search method of measuring the ride comfort. Shirahatti et al. [8] have employed genetic algorithm to find out the minimum acceleration and the road holding, and thus the results have been compared using the Simulink model. The existing methods in the field, namely, analytical, experimental, and computational methods have been studied and minimized in the combustion problem [9].

The comparison for the ride performance of the suspension system between the double mathematical modelling and experimental work for a quarter car model of the Proton Preve suspension system has not been studied comprehensively. Moreover, the passive suspension system focuses on the intelligence system with the mathematical modelling has not been touched upon. The comparison for the oscillation of travel displacement against time between the mathematical modelling and the experimental work has not been carried out as well. The study contributes the development of a new mathematical modelling for a quarter car model of the Proton Preve suspension system. This study also strives as a guideline of achieving a better automobile suspension system and the theories in the mathematical modelling could be applied to the car manufacturing industries.

The study aims to formulate a new mathematical modelling of the passive suspension system using the Proton Preve car model. The performance of the double passive automobile suspension system is examined using the graph plotted by Matlab software. For the validation, the result obtains from the mathematical modelling will be compared to the data produces from the experimental work. The comparison depicts using the Matlab software and further analysis uses the dispersion model. Meanwhile, the validation process also supports with the Ford Scorpio car model's study. The study is organized as follows: Sections 1 and 2 introduce the passive automobile suspension systemand the related literature reviews. The new mathematical modelling of the passive automobile suspension system yields the unique solution of the double passive suspension system is explained in Section 3. Sections 4 and 5 show the analyses of the vertical displacement between mathematical modelling and experimental systems. The study ends with a remarked conclusion in Section 6.

\section{Literature Review}

The suspension has an intention to protect the vehicle from the vibrations which occur when traveling on a rough road surface [10]. The other functions of a suspension system were to decrease the vibration energy that is induced in the body of a vehicle by road disturbances and to maintain the vehicle's stability within an acceptable range [11]. The ride comfort creates from the vertical acceleration produced by the car. The passenger's seat has been filtered through the process and the weight of the frequency was also the domain of the human sensitivity in relation to the vertical acceleration [12].

An effective suspension system can provide a greater protection with a lower level of concussive movement to the car body depending on the interaction with an uneven road surface [6]. Cars generally, have two suspension systems connected at the tandem to control the driving and braking forces in providing a smooth ride and comfort [13]. A majority of the present commercial vehicles that are built by the major manufacturers containing the passive suspension systems, which has a unique force for displacement or speed. This force characteristic was imposed by the characteristics of the constructive elements used in the passive suspension system to control the dynamics of the vehicle's vertical motion [14].

The car suspension has been classified into three types, namely, passive suspension systems, active suspension systems and semi-active suspension systems [15]. These types of the suspensions have a different operational mode in enhancing the safety of the vehicle, ride comfort and the overall performance of the car [16]. Numerous car models have been utilized these types of the suspension systems in the manufacturing such as the quarter car model, half car model and full car model [17]. 
The passive vehicle suspension systemconsists of the spring and damper. Damper uses to disperse the energy and spring acts as an energy storing element. Both elements were without any energy into the system like the type of an automobile suspension system or known as passive suspension system [18]. The system consists of the fixed parameters such as ride comfort, road holding and load conveying. The main problem of the suspension system is the damper design. If the damper has heavy loading, the car became an unbalanced mode on the road while if the damper has lightweight, the car achieved the stability mode even when turning or changing lane. The road profiles are also an important role in the performance of the suspension system. In the passive suspension system, the different types of spring are applied to the different vehicles. As highlighted in [19], the spring rate became high when the heavy suspension loads were used [19]. Moreover, if the spring stiffness increased, thus, the ride comfort decreased [20].

Passive suspensions are designed to satisfy the conflicting criteria of the ride comfort and vehicle handling. The main function of the car suspension systems was to minimize the vertical acceleration transmitted to the passenger by providing the road comfort [21]. Suspension system plays an important role in the performance of a vehicle to minimize the shocks acting upon the chassis and driver while maintaining the wheel road traction during the bump and droop conditions. One of the important features was the vehicle stability and driver's comfort, which satisfy through a strong suspension design [22]. Different types of the mathematical models have been developed for the different suspension systemof the vehicle. Different suspension systems were fulfilled the constraint of an energy efficiency using various approaches [23]. The quarter vehicle model was used as an initial investigation, in which the model was closely resembled the actual model of the car [24]. Ride safety and the handling capabilities of the vehicle are mainly determined by the suspension system which transmit the forces between the vehicle and the road.

The automobile industry predominantly uses the passive suspension systems due to its low cost and high reliability. However, this type of the suspension is typically designed with the limited functionality due to the constraints of the design parameters. In order to improve the vibration-suppression effects of the passive suspension, many studies have proposed the incorporation of an active actuator as the supplement to the passive device or also known as the active-passive-combined suspension system [25]. This approach, however, has been required a complicated learning mechanism or a specific performance decision table with the certain difficulties in the application [21].

From all the described reviews, the comparison results between the double mathematical modelling and experimental work in the quarter car model of the Proton Preve suspension system have not been comprehensively studied. However, only the passive suspension system has been studied using the intelligence system and undoubtedly, the mathematical modelling has not been explored yet. The review also notes that, there is no related study has been focused on the Proton Preve suspension system. Therefore, a double mathematical modelling is formulated and applied to the Proton Preve car could be awarded as a novel study. The modelling offers some beneficial aspects to the automobile suspension system and also giving a new knowledge and exploration to the related industry.

\section{Methods}

There were two common techniques to depict the verification and validation process related to the model development process [26]. A new mathematical model of the passive suspension system was produced using the Proton Preve car model. The mathematical modelling was utilized the second order linear differential equation.

The mathematical modelling using Proton Preve parameter was transformed into Matlab software in order to obtain a graph between the vertical displacement and time settlement. For the experimental work, the physical modelling was conducted using Proton Preve automobile suspension systems. The experiments were implemented to yield the real vertical displacement and time based on Proton Preve. Matlab software was also used to plot a graph between the vertical displacement and time from the experimental data. Moreover, the graph between the vertical displacement and time from the experimental work was a sinusoidal-shaped waveform pattern and was a graph reference when conducting the validation process.

The graph from the mathematical modelling was known as the proposed model graph while an actual graph was identified from experimental work. The proposed model was acceptable when the graph contained the similar pattern with the actual graph. At the moment, the error was equal to $0 \%$ since the 
patterns were identical. When the graph patterns were identical, the data henceforth consisted of the same characters. Further analysis was also conducted using the dispersion model. This analysis will be explained in Section 5.
Figure 1 shows the process flow diagram of the study. Every procedure was employed in both models, mathematical modelling and the experimental work.

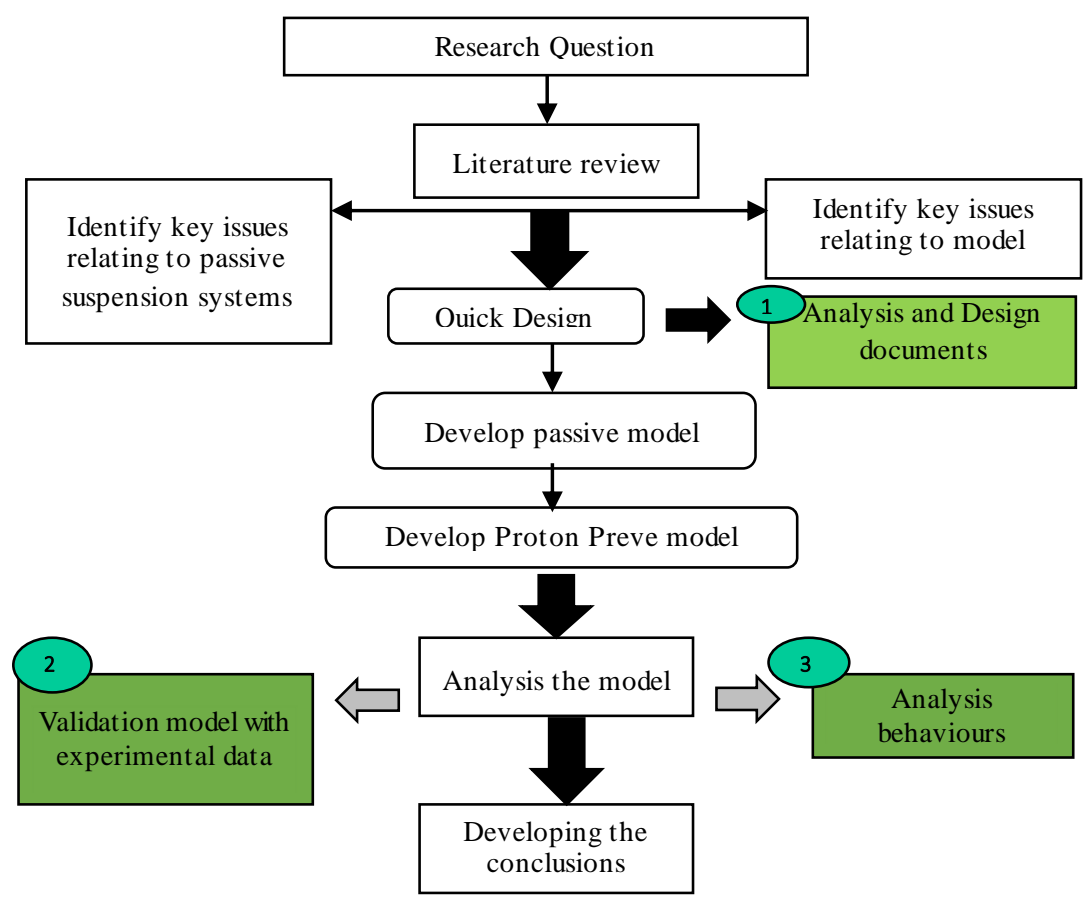

Figure 1 Process flow diagram of the study

3.1Mathematical modelling of the passive system The motion of the body and the wheel was controlled by the passive suspension system by limiting their relative velocities to a rate of the desired ride characteristics [17]. This system was performed by several types of the damping elements placed between the body and the wheels of the vehicle, such as hydraulic shock absorber. The model of the passive car suspension system was basically originated from Ford Scorpio model. The model applies the spring $(k)$, damper $(c)$ connected with the wheel mass $(m)$. Figure 2 depicts the model.

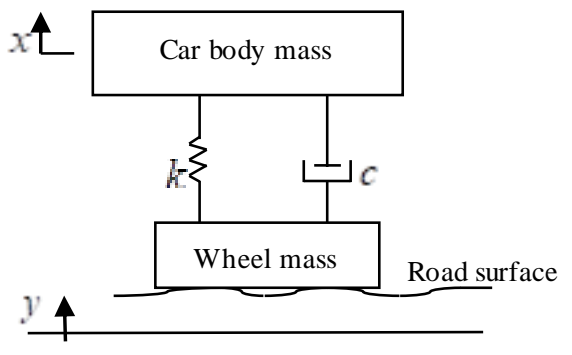

Figure 2 Car suspension model
Newton's second law of motion in a vertical direction was applied to derive the mathematical equations especially for describing the motions. By assuming the car body and the wheels move vertically upwards with the spring and damper expressed as

$X(t)=x-y$

where

$X(t)$ is an extension of the spring;

$x$ is the vertical displacement of the car body above its equilibrium position;

$y$ is the vertical displacement of the wheel (due to the road surface was measured with respect to some fixed horizontal line).

A mechanical element for spring was deformed by an external force when applying the force. The relationship between the acting force, $f$ and the displacement, $x$ written as

$F_{s}=k x(t)$

and the spring force denoted by

$F_{s}=k(x-y)$ 
where $F_{S}$ is a force of the spring, $k$ is a constant parameter and $x-y$ is an extension of the spring.

For the passive system, the system was dealt with a linear damping force. Given the damper force such as $F_{d}=c v$

where $F_{d}$ is a resisting force for damper, $c$ is a damping coefficient and $v$ is a relative velocity of the housing and the piston.

$v=\frac{d X(t)}{d t}=\frac{d(x-\mathrm{y})}{\mathrm{dt}}$

where

$X(t)$ is an extension of the spring;

$x$ is the vertical displacement of the car body above its equilibrium position;

$y$ is the vertical displacement of the wheel (due to the road surface was measured with respect to some fixed horizontal lines).

The first order differential equation in Equation (5) was modified to such as

$v=x^{\prime}(t)-y^{\prime}(t)$

Figure 3 shows the simplified model from Figure 2.

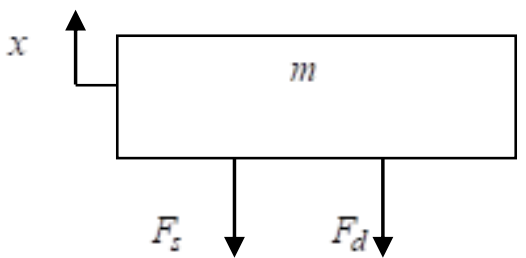

Figure 3 Damper and spring forces in car model

Figure 3 implies the Newton law of motion. The Newton's second law of motion was denoted as $f=m a$

where $f$ is a force, $m$ is a mass and $a$ is an acceleration.

Newton's second law was re-written using the second order of ordinary differential equation as

$m^{\prime \prime}(t)=-F_{s}(t)-F_{d}(t)$

Figure 4 depicts the road surface profile which contain the sinusoidal-shaped curve.

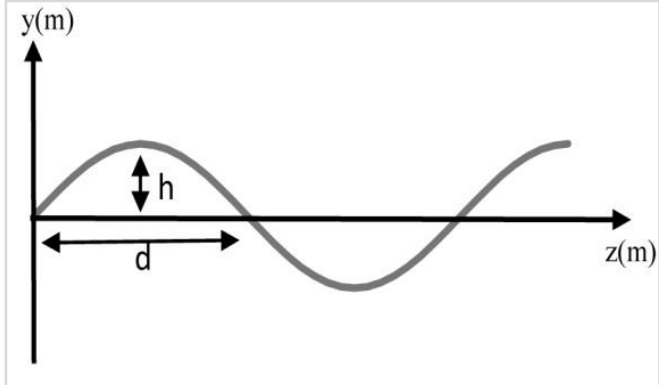

Figure 4 Sinusoidal-shaped curve in road surface profile

The sinusoidal-shaped curve in road surface profile was described as

$y=h \sin (\alpha z)$

where $h$ is an amplitude of the sinusoidal curve, $y$ is a vertical displacement of the wheel due to the road surface was measured with respect to some fixed horizontal datum lines and $z$ is a horizontal displacement. In the road profile by assuming the car was travelled with an average horizontal speed, $V$ as $z=V t$

Therefore,

$y(t)=h \sin \frac{\pi V t}{d}$

The differentiation of $y(t)$ was yielded as

$y^{\prime}(t)=h \frac{\pi V}{d} \cos \frac{\pi V t}{d}$

3.2 Development of the mathematical modelling for double passive suspension system

In order to verify the proposed model therefore, the parameter values of the car were employed. The following parameters of Proton Preve car model were such as:

$m=290 \mathrm{~kg}$;

$k=16812 \mathrm{Nm}^{-1}$;

$c=1000 \mathrm{Nsm}^{-1}$;

$V=14 m s^{-1}$;

$d=2 m$;

$h=0.1 m$.

Equation (8) was modified to yield the following equations:

$m^{\prime \prime}(t)=-k(x-y)-c\left(x^{\prime}(t)-y^{\prime}(t)\right)$

$m^{\prime \prime}(t)+c x^{\prime}(t)+k x(t)=k y+c y^{\prime}(t)$ 
S. H. Yahay a et al.

Equations (11) and (12) were substituted into Equation (14) to have

$290 x^{\prime \prime}(t)+1000 x^{\prime}(t)+16812 x(t)=1681.2 \sin (7 \pi t)+$ $700 \pi \cos (7 \pi t)$

Equation (15) was solved using nonlinear form such as

$X(t)=X_{p}(t)+X_{c}(t)$

where $X_{p}$ is a general particular solution and $X_{c}$ is a complementary solution.

Moreover, $X_{p}$ was solved using the following equations:

$290 m^{2}+1000 m+16812=0$

$m=\frac{-b \pm \sqrt{b^{2}-4 a c}}{2 a}$

$m=-1.724 \pm 7.416 i$

Equation (19) consisted of the root of the complex conjugate, therefore, $X_{p}$ was obtained as $X_{p}(t)=e^{-1.724 t}[a \cos (7.416) t+b \sin (7.416) t]$

The following equation was used in constructing $X_{c}$ became

$X_{c}(t)=k y(t)+c y^{\prime}(t)$

$X_{c}(t)=k \cdot h \sin \left(\frac{\pi v t}{d}\right)+c \cdot h\left(\frac{\pi t}{d}\right) \cos \left(\frac{\pi v t}{d}\right)$

The input parameters from Proton Preve car model were utilized and substituted into Equation (22) yielded as

$X_{c}(t)=\alpha \cos (7 \pi t)+\gamma \sin (7 \pi t)$

where $\alpha=c \cdot h\left(\frac{\pi t}{d}\right)$ and $\gamma=k \cdot h$

Equations (23) was differentiated and showed as

$\dot{X}_{c}(t)=7 \pi \gamma \cos (7 \pi t)-7 \alpha \sin (7 \pi t)$

and

$\ddot{X}_{c}(t)=-49 \pi^{2} \alpha \cos (7 \pi t)-49 \pi^{2} \gamma \sin (7 \pi t)(25)$

Equations (23), (24) and (25) were substituted into Equation (17) to have

$$
\begin{aligned}
290[-49 \pi \alpha \cos ( & 7 \pi t)-49 \pi \gamma \sin (7 \pi t)] \\
& +1000[7 \pi \gamma \cos (7 \pi t) \\
& -7 \pi \alpha \sin (7 \pi t)] \\
& +\quad 16812[\alpha \cos (7 \pi t) \\
& +\gamma \sin (7 \pi t)] \\
& =1681.2 \sin (7 \pi t) \\
& +700 \pi \cos (7 \pi t)
\end{aligned}
$$

Equation (26) was solved to obtain $\alpha$ and $\gamma$ such as

$-107992.92 \gamma-26389.38 \alpha=2500$

Therefore, $\alpha=-0.0196$ and $\gamma=-0.0101$

$\alpha$ and $\gamma$ values were substituted into Equation (23) produced as

$X_{c}(t)=-0.0196(7 \pi t)-0.0101 \sin (7 \pi t)$

Equations (28) and (20) were substituted into Equation (16) to have

$X(t)=e^{1.724 t}[a \cos (7.416) t+b \sin (7.416) t]-$

$0.0196 \cos (7 \pi \mathrm{t})-0.0101 \sin (7 \pi \mathrm{t})$

The following initial conditions were applied to determine $a$ and $b$ :

$X(0)=0 \& X^{\prime}(0)=0$

Thus,

$a=0.0196 \& b=0.345$

$a$ and $b$ values were substituted into Equation (29) depicted as

$X(t)=e^{-1.724 t}[0.0196 \cos (7.416) t+0.035 \sin (7.416) t]$

$-0.0196 \cos (7 \pi t)-0.0101 \sin (7 \pi t)$

\section{Results}

The main focus of the study was the measurement of the displacement denoted by $x(t) . x(t)$ was continued by plotting a graph using Matlab Software. For the validation process, the data from the model experimental work for quarter car model was employed.

Figure 5 shows the oscillation, $x(t)$ of the car body's from the experimental work indicated by the blue line and the oscillation, $x(t)$ of the car body's from the mathematical modelling indicated by the red-dotted line. Table 1 indicates the results for $x(t)$ in meter with time $(t)$ in second for the experimental work and the mathematical modelling. 


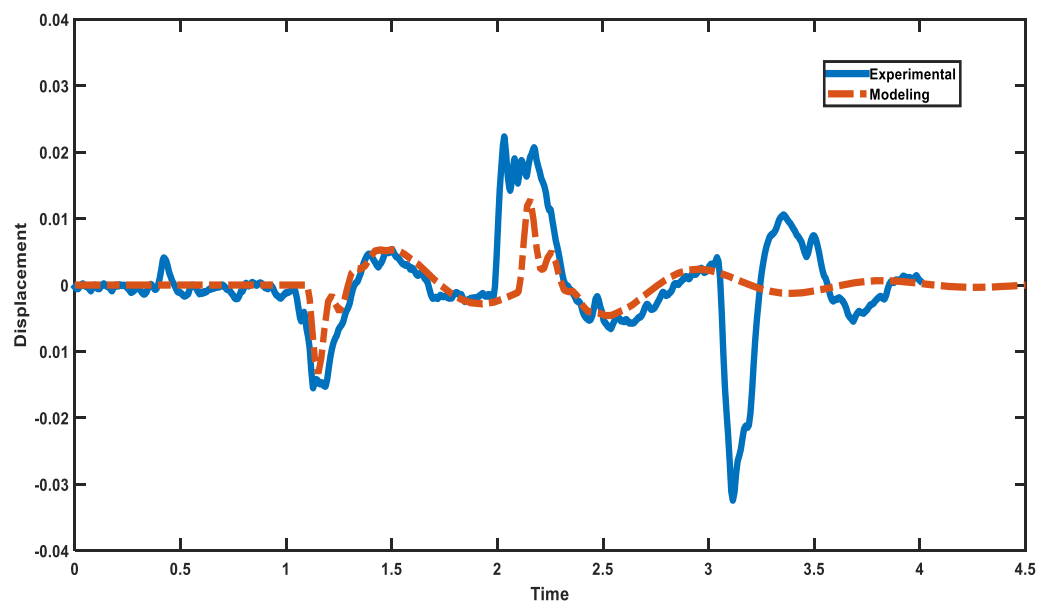

Figure $5 \mathrm{x}(t)$ Between mathematical modelling and experimental work

Table $1 x(t)$ With $t$ between mathematical modelling and experimental work

\begin{tabular}{lll}
\hline \hline $\boldsymbol{t}(\mathbf{s})$ & Experimental work & Mathematical modelling \\
\hline 0 & 0 & 0 \\
\hline 0.25 & 0 & 0 \\
\hline 0.50 & 0.005 & 0 \\
\hline 0.75 & -0.002 & 0 \\
\hline 1.00 & 0 & 0 \\
\hline 1.25 & -0.015 & $\mathbf{- 0 . 0 1 5}$ \\
\hline 1.50 & 0.005 & 0.005 \\
\hline 1.75 & -0.002 & -0.002 \\
\hline 2.00 & $\mathbf{0 . 0 2 0}$ & 0 \\
\hline 2.25 & 0.010 & $\mathbf{0 . 0 1 5}$ \\
\hline 2.50 & 0 & 0 \\
\hline 3.75 & -0.004 & -0.003 \\
\hline 3.00 & 0.004 & 0.003 \\
\hline 3.50 & $\mathbf{- 0 . 0 3 0}$ & -0.001 \\
\hline 3.75 & 0.010 & 0.001 \\
\hline 4.00 & -0.005 & 0 \\
\hline Mean & 0 & 0 \\
\hline
\end{tabular}

From the Table 1, the maximum $x(t)$ obtained from the experimental work was $0.02 \mathrm{~m}$ and $-0.03 \mathrm{~m}$ with the minimum $x(t)$. For a Mathematical modelling, the maximum $x(t)$ was $0.015 \mathrm{~m}$ while the minimum value was at $-0.015 \mathrm{~m}$. The mathematical modelling was showed that when starting at $t=2 \mathrm{~s}$, the stability region of the graph pattern was achieved and this finding was also supported by another finding using Ford Scorpio car model as shown in Figure 6. The graph shows that the consistency level at $t=2 \mathrm{~s}$ is similar as shown in the mathematical modelling. 
S. H. Yahay a et al.

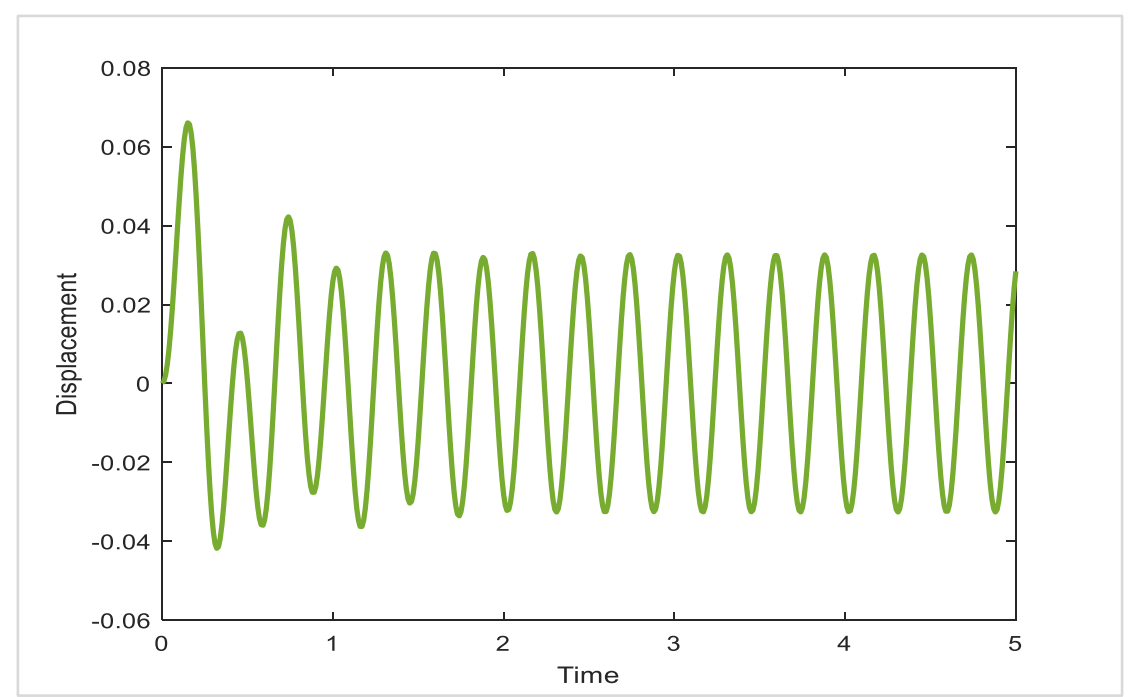

Figure $6 x(t)$ For Ford Scorpio car model

\section{Discussion}

$x(t)$ was a vertical displacement of the car body above to its equilibrium position represented by Proton Preve. Due to the model, $x(t)$ was the difference movement between the car body and the wheel. The reduction in $x(t)$ defined the car ride comfort was increasing significantly. The maximum displacement on the graphs was showed the spring of the car was expanding while the minimum value of the displacement was showed the spring was shrinking. These responses were occurred due to the spring was utilized to stabilize the car's body. For the stability region, both graphs were showed at $t=4 \mathrm{~s}$ where the systems were achieved the stabilization. The dispersion models namely, the standard deviation and mean were employed to evaluate the data accuracy either convergent or divergent type and also to find out the stability of the data. A small value for the standard deviation was indicated that the value tended to be close to the mean [24]. In this study, the standard deviation produced by the experimental work was 0.01 while the standard deviation from the mathematical modelling was 0.005 . Therefore, the value from the mathematical modelling was smaller than the experimental work. All the $x(t)$ produced by the mathematical modelling therefore, were tended to be closer to its mean which was 0.000176 (almost zero). When the zero $x(t)$ was achieved, lessvibrations were also happened. Therefore, the mathematical modelling had some potentials to be further explored in the future since the model reduced or controlled the vibration. Thus, the modelling had a good suspension system which can absorb the road impacts rapidly on the different road profiles. The modelling was also returned to its normal position 1190 while maintaining the contact between the tyres and the road surface. There were severe limitations of the study such as the similar parameters were used for the mathematical modelling and experimental work. This was due to remain the model accuracy when comparing both models. The accurate results were highly required for the study. Meanwhile, the study was applied a quarter car model for Proton Preve suspension systems became a pilot study however, a full car model of the suspension system will be considered for the future studies.

A complete list of abbreviations is shown in Appendix I.

\section{Conclusion and future work}

In the study, the mathematical modelling of the double passive suspension systems has been successfully developed and simulated for a quarter of Proton Preve car model. This modelling was formulated using the second-order differential equation and was analysed by plotting a graph and through the dispersion model. For the modelling accuracy, the suspension travel limit of the car's displacement and the stability of the system were validated using the data from the experimental work. The results were showed that the behaviour for the displacements produced from the mathematical model and the experimental work were identical. Less-vibration was happened when the zero displacement was produced by the mathematical modelling. Therefore, the mathematical modelling has been proven that the model can act as an important role to represent a passive model in Proton Preve car model and for future prediction in other applications. 
For a future study, a double Magneto-Rheological (MR) suspension systems using the Modified BoucWen model will be suggested and applied for a full car model. It would be more interesting to assess the greater results in the stability and the comfort of the car system using the suggestion.

\section{Acknowledgment}

This study was supported by Universiti Teknikal Malaysia Melaka and Ministry of Higher Education, Malaysia. The authors greatly acknowledge anyone who has contributed in giving helpful suggestions and comments.

\section{Conflicts of interest}

The authors have no conflicts of interest to declare.

\section{References}

[1] Florin A, Ioan-cozmin MR, Liliana P. Passive suspension modeling using MATLAB, quarter-car model, input signal step type. New Technologies and Products in Machine Manufacturing Technologies. 2013:258-63.

[2] Klinger F, Edelmann J, Plöchl M. Characterization and potential analysis of passive and (semi-) active suspension systems by means of equivalent suspension parameters. In international Munich chassis symposium 2020 (pp. 389-403). Springer Vieweg, Wiesbaden.

[3] Oyetunji OR, Adesope WA, Ufokima P, Salawu EY, Araoy inbo AO, Ishola FA. Design and fabrication of a pilot scale remote controlled electric car using additive manufacturing approach. International Journal of Emerging Trends in Engineering Research. 2020; 8(7):3054-7.

[4] Walavalkar S, Tandel V, Thakur RS, Kumar VP, Bhuran S. Performance comparison of various controllers on semi-active vehicle suspension system. In ITM web of conferences 2021 (pp.1-9). EDP Sciences.

[5] Kumar S, Medhavi A, Kumar R. Optimization of nonlinear passive suspension sy stem to minimize road damage for heavy goods vehicle. International Journal of Acoustics and Vibration. 2021; 26(1):56-63.

[6] Amin AZ, Ahmad S, Hoe YS. Electromagnetics car suspension system. Indian Journal of Science and Technology . 2016; 9(40):1-4.

[7] Pundir AS, Singh K, Dohare RK. Simulation of fixed bed cataly tic reactor through adomian decomposition method and reduced differential transform method. International Journal of Advanced Technology and Engineering Exploration. 2016; 3(22):131-6.

[8] Shirahatti A, Prasad PS, Panzade P, Kulkarni MM. Optimal design of passenger car suspension for ride and road holding. Journal of the Brazilian Society of Mechanical Sciences and Engineering. 2008; 30:6676.

[9] Nogueira E. The effectiveness method ( $\varepsilon-N T U)$ to analyze the thermal performance of the flat tube multilouvered finned radiator with silver nanoparticles suspension in ethylene gly col. International Journal of Advanced Technology and Engineering Exploration. 2020; 7(66):102-12.

[10] Yakhni MF, Ali MN, El-gohary MA. Magnetorheological damper voltage control using artificial neural network for optimum vehicle ride comfort. Journal of Mechanical Engineering and Sciences. 2021; 15(1):7648-61.

[11] Gad AS, El-zoghby HM, Oraby WA, El-demerdash SM. Performance and behaviour of a magnetorheological damper in a semi-active vehicle suspension and power evaluation. American Journal of Mechanical Engineering and Automation. 2018; 5(3):72-89.

[12] Borole KR, Sherje NP, Nagarkar MP. Mathematical modelling and analysis of tire-vehicle suspension system using matlab®. International Journal of Scientific Research in Science, Engineering and Technology. 2018; 4(1): 1262-8.

[13] Bhise AR, Desai RG, Yerrawar RN, Mitra AC, Arakerimath RR. Comparison between passive and semi-active suspension system using MATLAB/Simulink. IOSR Journal of Mechanical and Civil Engineering. 2016; 13(4):1-6.

[14] Manolache-rusu IC, Suciu C, Mihai I. Analysis of passive vs. semi-active quarter car suspension models. In advanced topics in optoelectronics, microelectronics and nanotechnologies X 2020. International Society for Optics and Photonics.

[15] Barethiye V, Pohit G, Mitra A. Modeling and analysis of passive suspension system using half car model based on hybrid shock absorber model. In proceedings of the international conference on vibration problems 2021 (pp. 1225-37). Springer, Singapore.

[16] Saad M, Akhtar S, Rathore AK, Begume Q, Reyazur-rahim M. Control of semi-active suspension system using PID controller. In IOP conference series: materials science and engineering 2018 (pp. 1-9). IOP Publishing.

[17] Nagarkar MP, El-gohary MA, Bhalerao YJ, Patil GJ, Patil RN. Artificial neural network predication and validation of optimum suspension parameters of a passive suspension system. SN Applied Sciences. 2019; 1(6):1-7.

[18] Shelke GD, Mitra AC, Varude VR. Validation of simulation and analytical model of nonlinear passive vehicle suspension system for quarter car. Materials Today: Proceedings. 2018; 5(9):19294302.

[19] Premandanda P, Dharmendra S. Review on air suspension system. In 3rd international conference on materials, manufacturing and modelling 2021.

[20] Mrazqua J. Chaibi R. Tissir EH. Ouahi M. Static output feedback stabilization of TS fuzzy active suspension systems. Journal of Terramechanics. 2021; 97:19-27.

[21] Amit, Khan N, Ali B. Analysis of active suspension svstem: a review. International Journal of Engineering Technology Science and Research, 2018; 5(5): 572-82. 
[22] Vashist A, Kumar R. Design and analysis of suspension system for an all-terrain vehicle. Materials Today: Proceedings. 2021.

[23] Nkomo LI, Dove A, Ngwako MT, Nyandoro OT. Heaviside based optimal control for ride comfort and actuation energy optimisation in half-car suspension sy stems. IFAC-PapersOnLine. 2017; 50(2):259-64.

[24] Kumar S, Medhavi A, Kumar R. Active and passive suspension system performance under random road profile excitations. International Journal of Acoustics \& Vibration. 2020; 25(4):532-41.

[25] Hu G, Liu Q, Ding R, Li G. Vibration control of semiactive suspension svstem with magnetorheological damper based on hyperbolic tangent model. Advances in Mechanical Engineering. 2017; 9(5):1-15.

[26] Sargent RG. Verification and validation of simulation models. In proceedings of the winter simulation conference 2010 (pp. 166-83). IEEE.

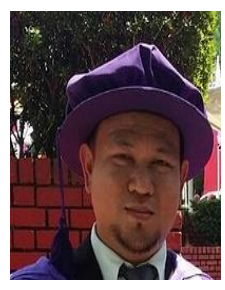

S. H. Yahaya Received a Ph.D. in Computer-Aided Geometrical Design from Universiti Sains Malaysia, Malaysia in 2015 and B.AS. and M.S. degrees in Mathematical Modeling from Universiti Sains Malaysia, Malaysia. He is currently an Assistant Professor in the Faculty of Manufacturing Engineering, Universiti Teknikal Malaysia Melaka, Malay sia.

Email:saifudin@utem.edu.my

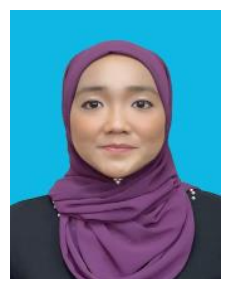

S. F. Yaakub Received B.S. and M.S. degrees in Industrial Mathematics from Universiti Teknologi Malaysia, Malaysia. She is currently a Ph.D. candidate in the Faculty of Manufacturing Engineering, Universiti Teknikal Malaysia Melaka, Malaysia.

Email: farizah1982@gmail.com

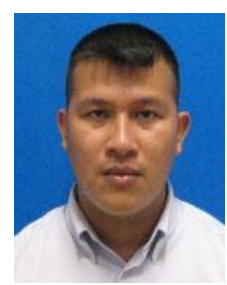

F. Ahmad Received a Ph.D. in Mechanical Engineering from Universiti Teknologi Malaysia, Malaysia in 2017 and B.E. and M.S. degrees in Mechanical Engineering from Universiti Teknikal Malaysia Melaka, Malaysia. He is currently an Assistant Professor in the Faculty of Mechanical Engineering, Universiti Teknikal Malaysia Melaka, Malaysia.

Email: fauzi.ahmad@utem.edu.my

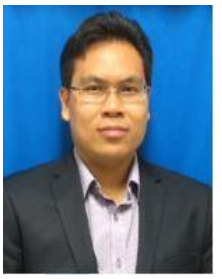

M. S. Salleh Received a Ph.D. in Mechanical Engineering from Universiti Kebangsaan Malaysia, Malaysia in 2015 and B.E. and M.S. degrees in Mechanical Engineering from Universiti Kebangsaan Malaysia and University of Conventry, UK, respectively. $\mathrm{He}$ is currently an Associate Professor in the Faculty of Manufacturing Engineering, Universiti Teknikal Malaysia Melaka, Malay sia.

Email: shukor@utem.edu.my

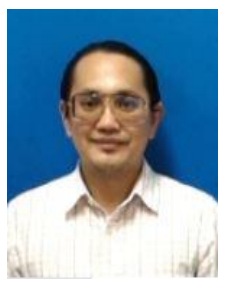

M. Y. Yuhazri Received a Ph.D. in Mechanical Engineering from Universiti Pertahanan Nasional Malaysia, Malaysia in 2014 and B.E. and M.S. degrees in Mechanical Engineering from Kolej Universiti Teknologi Tun Hussein Onn and Universiti Teknikal Malaysia Melaka, Malaysia, respectively. $\mathrm{He}$ is currently an Associate Professor in the Faculty of Mechanical and Manufacturing Engineering Technology, Universiti Teknikal Malaysia Melaka, Malay sia.

Email: yuhazri@utem.edu.my

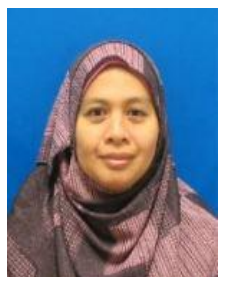

S. Akmal Received a Ph.D. in Mechanical Engineering from Toyohashi University of Technology, Japan in 2013 and B.E. and M.S. degrees in Mechanical Engineering from Universiti Islam Antarabangsa Malaysia and Technical University of Berlin, Germany, respectively. She is currently an Assistant Professor in the Faculty of Mechanical and Manufacturing Engineering Technology, Universiti Teknikal Malaysia Melaka, Malaysia. Email: suriatiakmal@utem.edu.my

Appendix 1

\begin{tabular}{llll}
\hline S. No. & Abbre viation & Description & \\
\hline 1 & ROVOP & $\begin{array}{l}\text { Rotating Square Evolutionary } \\
\text { Operation }\end{array}$ \\
\hline 2 & $\mathrm{x}(\mathrm{t})$ & Vertical Displacement \\
\hline 3 & $\mathrm{t}$ & Time & \\
\hline 4 & MR & Magneto-Rheological & \\
\hline
\end{tabular}

